(May contain scanning errors)

\title{
The Crisis of Professional Knowledge and the Pursuit of an Epistemology of Practice \\ Donald Schon
}

\section{Original Location}

Chapter 13, in Competence in the Learning Society, John Raven and John Stephenson (eds), published 2001 by Peter Lang, New York, pps 185-207

Reproduced on the HE Academy website by kind permission of

Peter Lang Publishing, Inc.

\section{Key words}

capability, professional practice, knowledge, epistemology, reflective practice

\section{Summary}

This chapter discusses the inadequacy of a technicist approach to professional knowledge for dealing with real-world practice situations and calls for an alternative, reflective epistemology of practice.

\begin{abstract}
About HEC: HEC was a national project of the Royal Society of Arts focused on encouraging higher education institutions to develop programmes that enabled students to become more personally capable, and to share their experiences with others. HEC was set up in 1988 and was hosted by Leeds University and Leeds Metropolitan University from 1991 to 1997 and by Middlesex University till 2004.
\end{abstract}

The HEC Archive comprises items submitted to national conferences, many of which have been published either in compilations or in HEC's journal, Capability. As such the HEC Archive provides insights into issues and initiatives during that period.

Downloaded from http://www.heacademy.ac.uk/

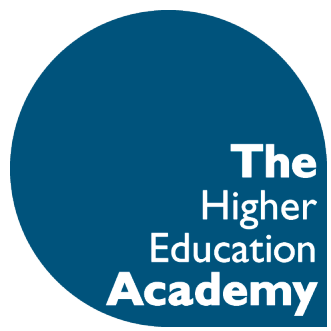




\title{
Chapter 13
}

\section{The Crisis of Professional Knowledge and the Pursuit of an Epistemology of Practice}

\author{
Donald Schon
}

Reprinted by permission of Harvard Business School Press. From Teaching and the Case Method, Instruction Guide, by Louis Bames, C. Roland Christensen with Abby J. Hansen, Boston, MA, 1987, pp. 241-254. Copyright@1984 by the President and Fellows of Harvard College, all rights reserved. This chapter, which the late Donald Schon sent to the editors for consideration for inclusion in this volume, is reproduced with the further permission of Mrs. Nancy Schon.

\section{Introduction: The Crisis of Confidence in Professional Knowledge}

Although our society has become thoroughly dependent on professionals, so much so that the conduct of business, industry, government, education, and everyday life would be unthinkable without them, there are signs of a growing crisis of confidence in the professions. In many well-publicized scandals, professionals have been found willing to use their special positions for private gain. Professionally designed solutions to public problems have had unanticipated consequences, sometimes worse than the problem they were intended to solve. The public has shown an increasing readiness to call for external regulation of professional practice. Laymen have been increasingly disposed to turn to the courts for defense against professional incompetence or venality. The professional's traditional claims to privileged social position and autonomy of practice have come into question as the public has begun to have doubts about professional ethics and expertise (Hughes, 1959). And in recent years, professionals themselves have shown signs of a loss of confidence in professional knowledge.

Yet, in 1963, the editors of Daedalus could introduce a special volume on the professions with the sentence, "Everywhere in American life the professions are triumphant" (Lynn, 1963). They noted the apparently limitless demand for professional services, the "shortages" of teachers and physicians, the difficulty of coordinating the proliferating technical specializations, the problem of managing the burgeoning mass of technical data. In the further essays which made up the volume, doctors, lawyers, scientists, educators, military men, and politicians articulated variations on the themes of professional triumph, overload, and growth. There were only two discordant voices. The representative of the clergy complained of declining influence and the "problem of relevance" , (Gustafson,

1963) and the city planner commented ruefully on his profession's lagging understandings of the changing ills of urban areas (Alonso, 1963). Yet in less than a decade the discordant notes had become the dominant ones and the themes of professional triumph had virtually disappeared.

In 1972, a colloquium on professional education was held at the Massachusetts Institute of Technology (MIT). Participants included distinguished representatives of the fields of medicine, engineering, architecture, planning, psychiatry, law, divinity, education, and 
management. These individuals disagreed about many things, but they held one sentiment in common-a profound uneasiness about their own professions. They questioned whether professionals would effectively police themselves. They wondered whether professionals were instruments of individual well-being and social reform or were mainly interested in the preservation of their own status and privilege, caught up in the very problems they might have been expected to solve. They allowed themselves to express doubts about the relevance and remedial power of professional expertise.

It is perhaps not very difficult to account for this dramatic shift, over a single decade, in the tone of professional self-reflection. Between 1963 and 1972 there had been a disturbing sequence of events, painful for professionals and lay public alike. A professionally instrumented war had been disastrous. Social movements for peace and civil rights had begun to see the professions as elitist servants of established interests. The much-proclaimed shortages of scientists, teachers, and physicians seemed to have evaporated. Professionals seemed powerless to relieve the rapidly shifting "crises" of the cities, poverty, environmental pollution, and energy. There were scandals of Medicare and, at the end of the decade, Watergate. Cumulatively, these events created doubts about professionally conceived strategies of diagnosis and cure. They pointed to the overwhelming complexity of the phenomena with which professionals were trying to cope. They led to skepticism about the adequacy of professional knowledge, with its theories and techniques, to cure the deeper causes of societal distress.

Sharing, in greater or lesser degree, these sentiments of doubt and unease, the participants in the MIT colloquium tried to analyze their predicament.

Some of them believed that social change had created problems ill-suited to the traditional division of labor. A noted engineer observed that "education no longer fits the niche, or the niche no longer fits education". The dean of a medical school spoke of the complexity of a huge healthcare system only marginally susceptible to the interventions of the medical profession. The dean of a school of management referred to the puzzle of educating managers for judgment and action under conditions of uncertainty.

Some were troubled by the existence of an irreducible residue of art in professional practice. The art deemed indispensable even to scientific research and engineering design seemed resistant to codification. As one participant observed, "If it's invariant and known, it can be taught; but it isn't invariant".

Professional education emphasized problem-solving, but the most urgent and intractable issues of professional practice were those of problem-finding. "Our interest", as one participant put it, "is not only how to pour concrete for the highway, but what highway to build? When it comes to designing a ship, the question we have to ask is, which ship makes sense in terms of the problems of transportation?"

And representatives of architecture, planning, social work, and psychiatry spoke of the pluralism of their schools. Different schools held different and conflicting views of the competences to be acquired, the problem to be solved, even of the nature of the professions themselves. A leading professor of psychiatry described his field as a "babble of voices".

Finally, there was a call for the liberation of the professions from the tyranny of the university-based professional schools. Everett Hughes, one of the founders of the sociology of the professions, declared that "American universities are the products of the late 19th and early 20th centuries. The question is, how do you break them up in some way, at least get some group of young people who are free of them? How do you make them free to do something new and different?" 
The years that have passed since the 1972 colloquium have tended to reinforce its conclusions. In the early 1980 s, no profession can celebrate young to embark on apparently secure and remunerative professional careers, professionals are still criticized, and criticize themselves, for failing to adapt to a changing social reality and to live up to their own standards of practice. There is widespread recognition of the absence or loss of a stable institutional framework of purpose and knowledge within which professionals can live out their roles and confidently exercise their skills.

In retrospect, then, it is not difficult to see why participants in the 1972 colloquium should have puzzled over the troubles of their professions. They were beginning to become aware of the indeterminate zones of practice-the situations of complexity and uncertainty, the unique cases that require artistry, the elusive task of problem-setting, the multiplicity of professional identities-that have since become increasingly visible and problematic. Nevertheless, there is something strange about their disquiet. For professionals in many different fields do sometimes find ways of coping effectively, even wisely, with situations of complexity and uncertainty. If the element of art in professional practice is not invariant, known, and teachable, it does appear occasionally to be learnable. Problem-setting is an activity in which some professionals engage with recognizable skill. And students and practitioners do occasionally make thoughtful choices from among the multiple views of professional identity.

Why, then, should a group of eminent professionals have been so troubled by the evidence of indeterminacy in professional practice?

It is not, I think, that they were unaware of the ways in which some practitioners cope reasonably well with situations of indeterminacy. Indeed, they might easily have counted themselves among those who do so. Rather, I suspect, they were troubled because they could not readily account for the coping process. Complexity and uncertainty are sometimes dissolved, but not by applying specialized knowledge to well-defined tasks. Artistry is not reducible to the exercise of describable routines. Problem-finding has no place in a body of knowledge concerned exclusively with problem-solving. In order to choose among competing paradigms of professional practice, one cannot rely on professional expertise. The eminent professionals were disturbed, I think, to discover that the competences they were beginning to see as central to professional practice had no place in their underlying model of professional knowledge.

In the following pages, I shall describe this underlying model, this implicit epistemology of practice, and I shall outline a fundamental dilemma of practice and teaching to which it leads. I shall propose that we seek an alternative epistemology of practice grounded in observation and analysis of the artistry competent practitioners sometimes bring to the indeterminate zones of their practice. I shall attempt a preliminary description and illustration of the "reflection-in-action" essential to professional artistry, and I shall suggest some of its implications for professional education.

\section{The Dominant Model of Professional Knowledge}

The epistemology of professional practice which dominates most thinking and writing about the professions, and is built into the very structure of professional schools and research institutions, has been clearly set forth in two essays on professional education. Both of these treat rigorous professional practice as an exercise of technical rationality, that is, as an application of research-based knowledge to the solution of problems of instrumental choice.

Edgar Schein (1974) proposes a threefold division of professional knowledge: 
- An underlying discipline or basic science component upon which the practice rests or from which it is developed.

- An applied science or "engineering" component from which many of the day-to-day diagnostic procedures and problem-solutions are derived.

- A skills and attitudinal component that concerns the actual performance of services to the client, using the underlying basic and applied knowledge.

In Schein's view, these components constitute a hierarchy which may be read in terms of application, justification, and status. The application of basic science yields engineering, which in turn provides models, rules and techniques applicable to the instrumental choices of everyday practice. The actual performance of services "rests on" applied science, which rests, in turn, on the foundation of basic science. In the epistemological pecking order, basic science is highest in methodological rigor and purity, its practitioners superior in status to those who practice applied science, problem-solving, or service delivery.

Nathan Glazer, in a much-quoted article, argues that the schools of such professions as social work, education, divinity, and town planning are caught in a hopeless predicament (Glazer, 1974). These "minor" professions, beguiled by the success of the "major" professions of law, medicine, and business, have tried to substitute a basis in scientific knowledge for their traditional reliance on experienced practice. In this spirit, they have placed their schools within universities. Glazer believes, however, that their aspirations are doomed to failure. The "minor" professions lack the essential conditions of the "major" ones. They lack stable institutional contexts of practice, fixed, and unambiguous ends which "settle men's minds" (Glazer, 1974), and a basis in systematic scientific knowledge. They cannot apply scientific knowledge to the solving of instrumental problems, and they are, therefore, unable to produce a rigorous curriculum of professional education.

Can these fields (education, city planning, social work, and divinity) settle on a fixed form of training, a fixed content of professional knowledge, and follow the models of medicine, law, and business? I suspect not because the discipline of a fixed and unambiguous end in a fixed institutional setting is not given to them. And thus (my emphasis) the base of knowledge which is unambiguously indicated as relevant for professional education is also not given (Glazer, 1974).

Glazer and Schein share an epistemology of professional practice rooted historically in the positivist philosophy which so powerfully shaped both the modern university and the modern conception of the proper relationship of theory and practice. (1) Rigorous professional practice is conceived as essentially technical. Its rigor depends on the use of describable, testable, replicable techniques derived from scientific research, based on knowledge that is objective, consensual, cumulative, and convergent. On this view, for example, engineering is an application of engineering science; rigorous management depends on the use of management science; and policy-making can become rigorous when it is based on policy-science.

Practice can be construed as technical, in this sense, only when certain things are kept clearly separate from one another. Deciding must be kept separate from doing. The rigorous practitioner uses his professional knowledge to decide on the means best suited to his ends, his action serving to "implement" technically sound decisions. Means must be clearly sepa 
rated from ends. Technical means are variable, appropriate or inappropriate according to the situation. But the ends of practice must be "fixed and unambiguous", like Glazer's examples of profit, health, and success in litigation; how is it possible otherwise to evolve a base of applicable professional knowledge? And finally, research must be kept separate from practice. For research can yield new knowledge only in the protected setting of the scholar's study or in the carefully controlled environment of a scientific laboratory, whereas the world of practice is notoriously unprotected and uncontrollable.

These tenets of the positivist epistemology of practice are still built into our institutions, even when their inhabitants no longer espouse them. Just as Thorstein Veblen propounded some 70 years ago, the university and the research institute are sheltered from the troublesome world of practice (Veblen, 1968). Research and practice are presumed to be linked by an exchange in which researchers offer theories and techniques applicable to practice problems, and practitioners, in return, give researchers new problems to work on and practical tests of the utility of research results. The normative curriculum of professional education, as Schein describes it, still follows the hierarchy of professional knowledge. First, students are exposed to the relevant basic science, then to the relevant applied science, and finally to a practicum in which they are presumed to learn to apply classroom knowledge to the problems of practice. Medical education offers the prototype for such a curriculum, and its language of "diagnosis", "cure", "laboratory", and "clinic" have long since diffused to other professions.

From the perspective of this model of professional knowledge, it is not difficult to understand why practitioners should be puzzled by their own performance in the indeterminate zones of practice. Their performance does not fit the criteria of technical rationality; it cuts across the dichotomies built into the positivist epistemology of practice. Artistry, for example, is not only in the deciding but also in the doing. When planners or managers convert an uncertain situation into a solvable problem, they construct - as John Dewey pointed out long ago - not only the means to be deployed but the ends-in-view to be achieved. In such problem-setting, ends and means are reciprocally determined. And often, in the unstable world of practice, where methods and theories developed in one context are unsuited to another, practitioners function as researchers, inventing the techniques and models appropriate to the situation at hand.

\section{The Dilemma of Rigor or Relevance}

For practitioners, educators, and students of the professions, the positivist epistemology of practice contributes to an urgent dilemma of rigor or relevance.

Given the dominant view of professional rigor, the view which prevails in the intellectual climate of the universities and is embedded in the institutional arrangements of professional education and research, rigorous practice depends on well-formed problems of instrumental choice to whose solution research-based theory and technique are applicable. (2) But real-world problems do not come well formed. They tend to present themselves, on the contrary, as messy, indeterminate, problematic situations. When a civil engineer worries about what road to build, for example, he does not have a problem he can solve by an application of locational techniques or decision theory. He confronts a complex and ill-defined situation in which geographic, financial, economic, and political factors are usually mixed up together. If he is to arrive at a well-formed problem, he must construct it from the materials of the problematic situation. And the problem of problem-setting is not a well-formed problem (Rein \& Schon, 1977). 
When a practitioner sets a problem, he chooses what he will treat as the "things" of the situation. He decides what he will attend to and what he will ignore. He names the objects of this attention and frames them in an appreciative context which sets a direction for action. A vague worry about hunger or malnourishment may be framed, for example, as a problem of selecting an optimal diet. But situations of malnourishment may also be framed in many different ways. (3) Economists, environmental scientists, nutrition scientists, agronomists, planners, engineers, and political scientists debate over the nature of the malnourishment problem, and their discussions have given rise to a multiplicity of problem-settings worthy of Rashomon. Indeed, the practice of malnourishment planning is largely taken up with the task of constructing the problem to be solved.

When practitioners succeed in converting a problematic situation to a well-formed problem, or in resolving a conflict over the proper framing of a practitioner's role in a situation, they engage in a kind of inquiry which cannot be subsumed under a model of technical problem-solving. Rather, it is through the work of naming and framing that the exercise of technical rationality becomes possible.

Similarly, the artistic processes by which practitioners sometimes make sense of unique cases, and the art they sometimes bring to everyday practice, do not meet the prevailing criteria of rigorous practice. Often, when a competent practitioner recognizes in a maze of symptoms the pattern of a disease, constructs a basis for coherent design in the peculiarities of a building site, or discerns an understandable structure in a jumble of materials, he does something for which he cannot give a complete or even a reasonably accurate description. Practitioners make judgments of quality for which they cannot state adequate criteria, display skills for which they cannot describe procedures or rules.

By defining rigor only in terms of technical rationality, we exclude as non-rigorous much of what competent practitioners actually do, including the skillful performance of problem-setting and judgment on which technical problem-solving depends. Indeed, we exclude the most important components of competent practice.

In the varied topography of professional practice, there is a high, hard ground which overlooks a swamp. On the high ground, manageable problems lend themselves to solution through the use of research-based theory and technique. In the swampy lowlands, problems are messy and confusing and incapable of technical solution. The irony of this situation is that the problems of the high ground tend to be relatively unimportant to individuals or to society at large, however great their technical interest may be, while in the swamp lie the problems of greatest human concern. The practitioner is confronted with a choice. Shall he/she etc remain on the high ground where he can solve relatively unimportant problems according to his standards of rigor, or shall he descend to the swamp of important problems and non-rigorous inquiry?

Consider medicine, engineering, and agronomy, three of Glazer's major or near-major professions. In these fields, there are areas in which problems are clearly defined, goals are relatively fixed, and phenomena lend themselves to the categories of available theory and technique. Here, practitioners can function effectively as technical experts. But when one or more of these conditions is lacking, competent performance is no longer a matter of exclusively technical expertise. Medical technologies like kidney dialysis or tomography have created demands which stretch the nation's willingness to invest in medical care. How should physicians behave? How should they try to influence or accommodate to health policy? Engineering solutions which seem powerful and elegant when judged from a relatively narrow perspective may have a wider range of consequences which degrade the environment, generate unacceptable risk, or put 
excessive demands on scarce resources. How should engineers take these factors into account in their actual designing? When agronomists recommend efficient methods of soil cultivation that favor the use of large land-holdings, they may determine the viability of the small family farms on which peasant economies depend. How should the practice of agronomy take such considerations into account? These are not problems, properly speaking, but problematic situations from which problems must be constructed. If practitioners choose not to ignore them, they must approach them through kinds of inquiry which are, according to the dominant model of technical rationality, unrigorous.

The doctrine of technical rationality, promulgated and maintained in the universities and especially in the professional schools, infects the young professional-in-training with a hunger for technique. Many students of urban planning, for example, are impatient with anything other than "hard skills". In schools of management, students often chafe under the discipline of endless case analysis; they want to learn the techniques and algorithms which are, as they see it, the key to high starting salaries. Yet a professional who really tried to confine his practice to the rigorous applications of research-based technique would find not only that he could not work on the most important problems but that he could not practice in the real world at all.

Nearly all professional practitioners experience a version of the dilemma of rigor or relevance, and they respond to it in one of several ways. Some of them choose the swampy lowland, deliberately immersing themselves in confusing but crucially important situations. When they are asked to describe their methods of inquiry, they speak of experience, trial and error, intuition or muddling through. When teachers, social workers, or planners operate in this vein, they tend to be afflicted with a nagging sense of inferiority in relation to those who present themselves as models of technical rigor. When physicians or engineers do so, they tend to be troubled by the discrepancy between the technical rigor of the "hard" zones of their practice and the apparent sloppiness of the "soft" ones.

Practitioners who opt for the high ground confine themselves to a narrowly technical practice and pay a price for doing so. Operations research, systems analysis, policy analysis, and some management sciences are examples of practices built around the use of formal, analytic models. In the early years of the development of these professions, following World War II, there was a climate of optimism about the power of formal models to solve real-world problems. In subsequent decades, however, there was increasing recognition of the limited applicability of formal models, especially in situations of high complexity and uncertainty (Ackoff, 1979). Some practitioners have responded by confining themselves to a narrow class of well-formed problems-in inventory control for example. Some researchers have continued to develop formal models for use in problems of high complexity and uncertainty, quite undeterred by the troubles incurred whenever a serious attempt is made to put such models into practice. They pursue an agenda driven by evolving questions of modeling theory and techniques, increasingly divergent from the contexts of actual practice.

Practitioners may try, on the other hand, to cut the situations of practice to fit their models, employing for this purpose one of several procrustean strategies. They may become selectively inattentive to data incongruent with their theories, (4) as some educators preserve their confidence in "competency-testing" by ignoring the kinds of competence that competency-testing fails to detect. Physicians or therapists may use junk categories like "patient resistance" to explain away the cases in which an indicated treatment fails to lead to cure (Geertz, 1973). And social workers may try to make their technical expertise 
effective by exerting unilateral control over the practice situation, for example, by removing "unworthy" clients from the case rolls.

Those who confine themselves to a limited range of technical problems on the high ground, or cut the situations of practice to fit available techniques, seek a world in which technical rationality works. Even those who choose the swamp tend to pay homage to prevailing models of rigor. What they know how to do, they have no way of describing as rigorous.

Writers about the professions tend to follow similar paths. Both Glazer and Schein, for example, recognize the indeterminate zones of professional practice. But Glazer relegates them to the "minor" professions, of which he despairs. And Schein locates what he calls "divergent" phenomena of uncertainty, complexity, and uniqueness in concrete practice situations, while at the same time regarding professional knowledge as increasingly "convergent". He thinks convergent knowledge may be applied to divergent practice through the exercise of "divergent skills" -about which, however, he is able to say very little (Schein, 1974). For if divergent skills were treated in terms of theory or technique, they would belong to convergent professional knowledge; and if they are neither theory nor technique, they cannot be described as "knowledge" at all. Rather, they function as a kind of junk category which serves to protect an underlying model of technical rationality.

Yet the epistemology of practice embedded in our universities and research institutions, ingrained in our habits of thought about professional knowledge, and at the root of the dilemma of rigor or relevance, has lost its hold on the field that nurtured it. Among philosophers of science, no one wants any longer to be called a positivist. (5) There is a rebirth of interest in the ancient topics of craft, artistry, and myth, topics whose fate positivism seemed once to have finally sealed. Positivism and the positivist epistemology of practice now seem to rest on a particular view of science, one now largely discredited.

It is timely, then, to reconsider the question of professional knowledge. Perhaps there is an epistemology of practice which takes full account of the competence practitioners sometimes display in situations of uncertainty, complexity, and uniqueness. Perhaps there is a way of looking at problem-setting and intuitive artistry which presents these activities as describable and susceptible to a kind of rigor that falls outside the boundaries of technical rationality.

\section{Reflection-in-Action}

When we go about the spontaneous, intuitive performance of the actions of everyday life, we show ourselves to be knowledgeable in a special way. Often, we cannot say what we know. When we try to describe it, we find ourselves at a loss, or we produce descriptions that are obviously inappropriate. Our knowing is ordinarily tacit, implicit in our patterns of action and in our feel for the stuff with which we are dealing. It seems right to say that our knowing is in our action. And similarly, the workaday life of the professional practitioner reveals, in its recognitions, judgments and skills, a pattern of tacit knowing-in-action.

Once we put technical rationality aside, thereby giving up our view of competent practice as an application of knowledge to instrumental decisions, there is nothing strange about the idea that a kind of knowing is inherent in intelligent action. Common sense admits the category of know-how, and it does not stretch common sense very much to say that the know-how is in the action-that a tightrope walker's know-how, for example, lies in, and is revealed by, the way he takes his trip across the wire, or that a big league pitcher's know-how is in his way of pitching to a batter's weakness, changing his pace, or 
distributing his energies over the course of a game. There is nothing in common sense to make us say that know-how consists in rules or plans which we entertain in the mind prior to action. Although we sometimes think before acting, it is also true that in much of the spontaneous behavior of skillful practice we reveal a kind of knowing which does not stem from a prior intellectual operation.

As Gilbert Ryle (1949) put it:

"What distinguishes sensible from silly operations is not their parentage but their procedure, and this holds no less for intellectual than for practical performances. "Intelligent" cannot be defined in terms of "intellectual" or "knowing how" in terms of "knowing that"; "thinking what I am doing" does not connote "both thinking what to do and doing it". When I do something intelligently . . I I am doing one thing and not two. My performance has a special procedure or manner, not special antecedents."

Andrew Harrison (1978) has expressed a similar thought by saying that when someone acts intellectually, he "acts his mind".

Examples of intelligence in action include acts of recognition and judgment, as well as the exercise of ordinary physical skills.

Michael Polany (1967) has written about our ability to recognize a face in a crowd. The experience of recognition can be immediate and holistic. We simply see, all of a sudden, the face of someone we know. We are aware of no antecedent reasoning and we are often unable to list the features that distinguish this face from the hundreds of others present in the crowd.

When the thing we recognize is "something wrong" or "something right", then recognition takes the form of judgment. Chris Alexander has called attention to the innumerable judgments of "mismatch"-deviations from a tacit norm-that are involved in the making of a design (Alexander, 1964). And Geoffrey Vickers has gone on to note that not only in artistic judgment but in all our ordinary judgments of quality, we "can recognize and describe deviations from a norm very much more clearly than we describe the norm itself" (Vickers, 1978). A young friend of mine who teaches tennis observes that his students have to be able to feel when they're hitting the ball right, and they have to like that feeling, as compared to the feeling of hitting it wrong, but they need not, and usually cannot, describe either the feeling of hitting it right or what they do to get that feeling. A skilled physician can sometimes recognize "a case of . . ." the moment a person walks into his office. The act of recognition comes immediately and as a whole; the physician may not be able to say, subsequently, just what led to his initial judgment.

Polany has described our ordinary tactile appreciation of the surface of materials. If you ask a person what he feels when he explores the surface of a table with his hand, he is apt to say that the table feels rough or smooth, sticky or slippery, but he is unlikely to say that he feels a certain compression and abrasion of his fingertips-though it must be from this kind of feeling that he gets to his appreciation of the table's surface. Polany speaks of perceiving from these fingertip sensations to the qualities of the surface. Similarly, when we use a stick to probe a hidden place, we focus not on the impressions of the stick on our hand but on the qualities of the place which we apprehend through these tacit impressions. To become skilful in the use of a tool is to learn to appreciate, as it were, directly, the qualities of materials that we apprehend through the tacit sensations of the tool in our hand.

Chester Barnard (1968) has written of "non-logical processes" that we cannot express in words as a process of reasoning, but evince only by a judgment, decision, or action. A child who has learned to throw a ball makes immediate judgments of distance which he 
coordinates, tacitly, with the feeling of bodily movement involved in the act of throwing. A high-school boy, solving quadratic equations has learned spontaneously to carry out a program of operations that he cannot describe. A practiced accountant of Barnard's acquaintance could take a balance sheet of considerable complexity and within minutes or even seconds get a significant set of facts from it, though he could not describe in words the recognitions and calculations that entered into his performance. Similarly, we are able to execute spontaneously such complex activities as crawling, walking, riding a bicycle, or juggling, without having to think, in any conscious way, what we are doing, and often without being able to give a verbal description even approximately faithful to our performance.

In spite of their tacit complexity and virtuosity, however, our spontaneous responses to the phenomena of everyday life do not always work. Sometimes our knowing-in-action yields surprises. And we often react to the unexpected by a kind of on-the-spot inquiry which I shall call reflection-in-action.

Sometimes this process takes the form of ordinary, on-line problem-solving. It need not even be associated with a high degree of skill but may consist in an amateur's effort to acquire skill. Recently, for example, I built a wooden gate. The gate was made of wooden pickets and strapping. I had made a drawing of it, and figured out the dimensions I wanted, but I had not reckoned with the problem of keeping the structure square. I noticed, as I began to nail the strapping to the pickets that the whole thing wobbled. I knew that when I nailed in a diagonal piece, the structure would become rigid. But how would I be sure that, at that moment, the structure would be square? I stopped to think. There came to mind a vague memory about diagonals-that in a square, the diagonals are equal. I took a yard stick, intending to measure the diagonals, but I found it difficult to make these measurements without disturbing the structure. It occurred to me to use a piece of string. Then it became apparent that I needed precise locations from which to measure the diagonal from corner to corner. After several frustrating trials, I decided to locate the center point at each of the corners (by crossing diagonals at each corner), hammered in a nail at each of the four center points, and used the nails as anchors for the measurement string. It took several moments to figure out how to adjust the structure so as to correct the errors I found by measuring, and when I had the diagonal equal, I nailed in the piece of strapping that made the structure rigid.

Here-in an example that must have its analogues in the experience of amateur carpenters the world over-my intuitive way of going about the task led me to a surprise the discovery of the wobble\} which I interpreted as a problem. Stopping to think, I invented procedures to solve the problem, discovered further unpleasant surprises, and made further corrective inventions, including the several minor inventions necessary to make the idea of string-measurement of diagonals work.

Ordinarily, we might call such a process "trial and error". But it is not a series of random trials continued until a desired result has been produced. The process has a form, an inner logic according to which reflection on the unexpected consequences of one action influences the design of the next one. The "moments" of such a process may be described as follows:

- In the context of the performance of some task, the performer spontaneously initiates a routine of action that produces an unexpected outcome.

- The performer notices the unexpected result which he construes as a surprise-an error to be corrected, an anomaly to be made sense of, an opportunity to be exploited. 
- Surprise triggers reflection, directed both to the surprising outcome and to the knowing-in-action that led to it. It is as though the performer asked himself, what is this?, and at the same time, what understandings and strategies of mine have led me to produce this?

- The performer restructures his understanding of the situation-his framing of the problem he has been trying to solve, his picture of what is going on, or the strategy of action he has been employing.

- On the basis of this restructuring, he invents a new strategy of action.

- He tries out the new action he has invented, running an on-the-spot experiment whose results he interprets, in turn, as a "solution", an outcome on the whole satisfactory, or else as a new surprise that calls for a new round of reflection and experiment.

In the course of such a process, the performer "reflects", not only in the sense of thinking about the action he has undertaken and the result he has achieved, but in the more precise sense of turning his thought back on the knowing-in-action implicit in his action. He reflects "in action" in the sense that his thinking occurs within the boundaries of what I call an action-present-a stretch of time within which it is still possible to make a difference to the outcomes of action.

These are examples of reflection-in-action drawn from some of the familiar contexts of professional practice:

- A designer, hard at work on the design of a school, has been exploring the possible configurations of small, classroom units. Having tried a number of these, dissatisfied with the formal results, she decides that these units are "too small to do much with". She tries combining the classrooms in L-shaped pairs and discovers that these are "formally much more significant" and that they have the additional, unexpected educational advantage of putting grade one next to grade two and grade three next to grade four.

- A teacher has a young student, Joey, who disturbs her by insisting that an eclipse of the sun did not take place because "it was snowing and we didn't see it". It occurs to the teacher that Joey does not know that the sun is there, even if he can't see it, and she asks him,

"Where was the sun yesterday"? Joey answers, "I don't know; I didn't see it". Later, it occurs to her that his answer may have reflected, not his ignorance of the sun remaining in the sky, but his interpretation of her question. She thinks that he may have read her as asking, Where in the sky was the sun? With this in mind, she tries a new question: "What happened to the sun yesterday"?, to which Joey answers, "It was in the sky".

In such examples as these, reflection-in-action involves a "stop-and-think". It is close to conscious awareness and is easily put into words. Often, however, reflection-in-action is smoothly embedded in performance; there is no stop-and-think, no conscious attention to the process, and no verbalization. In this way, for example, a baseball pitcher adapts his pitching style to the pecularities of a batter, a tennis player executes split-second variations in play in order to counter the strategies of his opponent. In such cases, we are close to processes we might recognize as examples of artistry.

When good jazz musicians improvise together, they display a feel for the performance. Listening to one another and to themselves, they feel where the music is going and adjust their playing accordingly. They are inventing on-line, and they are also responding to 
surprises provided by the inventions of the others. A figure announced by one performer will be taken up by another, elaborated, and perhaps integrated with a new melody.

The collective process of musical invention is not usually undertaken at random, however. It is organized around an underlying structure-a shared schema of meter, melody, and harmony that gives the piece a predictable order. In addition, each of the musicians has ready a repertoire of musical figures that he can play, weaving variations of them as the opportunity arises. Improvisation consists in varying, combining, and recombining a set of figures within the schema that gives coherence to the whole performance. As the musician feels the directions in which the music is developing, out of their interwoven contributions, they make new sense of it and adjust their performances to the sense they make. They are reflecting-inaction on the music they are collectively making, though not, of course, in the medium of words.

Their process is not unlike the familiar improvisation of everyday conversation, which does occur in the medium of words. A good conversation is both predictable and, in some respects, unpredictable. The participants may pick up themes suggested by others, developing them through the associations they provoke. Each participant seems to have a readily available repertoire of kinds of things to say, around which we can develop variations suited to the present occasion. Conversation is collective verbal improvisation which tends to fall into conventional routines-for example, the anecdote (with appropriate side comments and reactions) or the debate-and it develops according to a pace and rhythm of interaction that the participants seem, without conscious attention, to work out in common. At the same time, there are surprises, in the form of unexpected turns of phrase or directions of development. Participants make on-the-spot responses to surprise, often in conformity to the kind of conversational role they have adopted. Central to the other forms of improvisation, there is a conversational division of labor that gradually establishes itself, often without conscious awareness on the part of those who work it out.

In the on-the-spot improvisation of a musical piece or a conversation, spontaneous reflection-in-action takes the form of a kind of production. The participants are involved in a collective making process. Out of the "stuff" of this musical performance, or this talk, they make a piece of music, or a conversation-in either case, an artifact that has, in some degree, order, meaning, development, coherence. Their reflection-in-action becomes a reflective conversation-this time, in a metaphorical sense with the materials of the situation in which they are engaged. Each person, carrying out his own evolving role in the collective performance, "listens" to the things that happen, including the surprises that result from earlier moves, and responds, on-line, through new moves that give new directions to the development of the artifact. The process is reminiscent of Carpenter's description of the Eskimo sculptor, patiently carving a reindeer bone, examining the gradually changing shape, finally exclaiming, "Ah seal"!

That one can engage in spontaneous reflection-in-action without being able to give a good description of it is evident from experience. Typically, when a performer is asked to talk about the reflection and on-the-spot experimenting he has just carried out, he gives at first a description which is obviously incomplete or inaccurate. And by comparing what he says to what he has just done, he can often discover this for himself.

Clearly, it is one thing to engage spontaneously in a performance that involves reflection-in-action, and quite another thing to reflect on that reflection-in-action through an act of description. It is still another thing to reflect on the resulting description. Indeed, these several, distinct kinds of reflection can play important roles in the process by which an individual learns a new kind of performance. A tennis coach (Galloway) reports his use of an exercise in which he repeatedly asks his students to "say where their racket was 
when they hit the ball"; he intends to help them get more precisely in touch with what they are doing when they hit the ball, so that they will know what they are doing when they try to correct their errors. Seymour Papert used to teach juggling by informing would-be jugglers that they are susceptible to a variety of kinds of "bugs" that is, to typical mistakes ("bugs" by analogy with computer programming)-such as "throwing too far forward" or "overcorrecting" an error. He would ask them from time to time to describe the "bug" they had just enacted.

Professional practitioners, such as physicians, managers, and teachers, also reflect-in-action, but their reflection is of a kind particular to the special features of professional practice. "Practice" has a double meaning. A lawyer's practice includes the kinds of activities he carries out, the clients he serves, the cases he is called upon to handle. When we speak of practicing the performance, on the other hand, we refer to the repetitive yet experimental process by which one learns, for example, to play a musical instrument. The two senses of "practice", although quite distinct, relate to one another in an interesting way. Professional practice also includes repetition. A professional is, at least in some measure, a specialist. He deals with certain types of situations, examples, images, and techniques. Working his way through many variations of a limited number of cases, he "practices" his practice. His know how tends to become increasingly rich, efficient, tacit, and automatic, thereby conferring on him and his clients the benefits of specialization. On the other hand, specialization can make him narrow and parochial, inducing a kind of overlearning which takes the form of a tacit pattern of error to which he becomes selectively inattentive.

Reflection on spontaneous reflection-in-action can serve as a corrective to overlearning. As a practitioner surfaces the tacit understandings that have grown up around the repetitive experiences of a specialized practice, he may allow himself to notice and make new sense of confusing and unique phenomena.

A skillful physician, lawyer, manager, or architect continually engages in a process of appreciating, probing, modeling, experimenting, diagnosing, psyching out, and evaluating, which he can describe imperfectly if at all. His knowing-in-action is revealed and presented by his feel for the stuff with which he deals. When he tries, on rare occasions, to say what he knows-when he tries to put his knowing into the form of knowledge his formulations of principles, theories, maxims and rules of thumb are often incongruent with the understanding and know-how implicit in his patterns of practice.

On the other hand, contrary to Hannah Arendt's observation that reflection is out of place in action, skillful practitioners sometimes respond to a situation that is puzzling, unique, or conflicted, by reflecting at one and the same time on the situation before them and on the reflection-inaction they spontaneously bring to it. In the midst of action, they are able to turn thought back on itself, surfacing, criticizing and restructuring the thinking by which they have spontaneously tried to make the situation intelligible to themselves. There are, for example:

- Managers who respond to turbulent situations by constructing and testing a model of the situation and experimenting with alternative strategies for dealing with it.

- Physicians who, finding that " $80 \%$ of the cases seen in the office are not found in the book", treat each patient as a unique case, constructing and testing diagnoses, inventing and evaluating lines of treatment through processes of on-the-spot experiment. 
- Engineers who discover that they cannot apply their rules of thumb to a situation because it is anomalous or peculiarly constrained (like the shattering of windows on the John Hancock building in Boston), and proceed to devise and test theories and procedures unique to the situation at hand.

- Lawyers who construct new ways to assimilate a puzzling case to a body of judicial precedent.

- Bankers who feel uneasy about a prospective credit risk, even though his "operating numbers" are all in order, and try to discover and test the implicit judgments underlying their uneasiness.

- Planners who treat their plans as tentative programs for inquiry, alert to discovering the unanticipated meanings their interventions turn out to have for those affected by them.

Many such examples of reflection on reflection-in-action occur in the indeterminate zones of practice-uncertain, unique, or value-conflicted. Depending on the context and the practitioner, such inquiry may take the form of on-the-spot problem-solving, or it may take the form of theory building, or reappreciation of the problem of the situation. When the problem at hand proves resistant to readily accessible solutions, the practitioner may rethink the approach he has been taking and invent new strategies of action. When he encounters a situation that falls outside his usual range of descriptive categories, he may surface and criticize his initial understandings and proceed to construct a new, situation-specific theory of the phenomena before him. (The best theories, Kevin Lynch observed, are those we make up in the situation.) When he finds himself stuck, he may decide that he has been working on the wrong problem, and evolve a new way of setting the problem.

The objects of reflection may be anywhere in the system of understanding and know-how that a practitioner brings to his practice. Depending on the centrality of the elements he chooses to surface and rethink, more or less of that system may become vulnerable to change. But, systems of intuitive knowing are dynamically conservative, actively defended, and highly resistant to change. They tend not to go quietly to their demise, and reflection-in-action often takes on a quality of struggle. In the early minutes and hours of the "accident" at the Three Mile Island nuclear power plant, for example, operators and managers found themselves confronted with combinations of signals they could only regard as "weird", unprecedented, unlike anything they had ever seen before.(6) Yet they persisted in attempting to assimilate these strange and perplexing signals to a situation of normalcy-"not wanting to believe", as one manager put it, that the nuclear core had been uncovered and damaged. Only after 12 hours of fruitless attempts to construe the situation as a minor problem - a breach in a steam line, a build-up of steam in the primary circulatory system - did one anonymous key manager insist, against the wishes of others in the plant, that "future actions be based on the assumption that the core has been uncovered, the fuel severely damaged".

Many practitioners, locked into a view of themselves as technical experts, find little in the world of practice to occasion reflection. For them, uncertainty is a threat; its admission, a sign of weakness. They have become proficient at techniques of selective inattention, the use of junk categories to dismiss anomalous data, procrustean treatment of troublesome situations, all aimed at preserving the constancy of their knowing-in-action. Yet reflection-in-action is not a rare event. There are teachers, managers, engineers, and artists for whom reflection-in-action is the "prose" they speak as they display and develop 
the ordinary artistry of their everyday lives. Such individuals are willing to embrace error, accept confusion, and reflect critically on their previously unexamined assumptions. Nevertheless, in a world where professionalism is still mainly identified with technical expertise, even such practitioners as these may feel profoundly uneasy because they cannot describe what they know how to do, cannot justify it as a legitimate form of professional knowledge, cannot increase its scope or depth or quality, and cannot with confidence help others to learn it.

For all of these reasons, the study of professional artistry is of critical importance. We should be turning the puzzle of professional knowledge on its head, not seeking only to build up a science applicable to practice but also to reflect on the reflection-in-action already embedded in competent practice.

We should be exploring, for example, how the on-the-spot experimentation carried out by practicing architects, physicians, engineers and managers is like, and unlike, the controlled experimentation of laboratory scientists. We should be analyzing the ways in which skilled practitioners build up repertoires of exemplars, images and strategies of description in terms of which they learn to see novel, one-of-a-kind phenomena. We should be attentive to differences in the framing of problematic situations and to the rare episodes of frame-reflective discourse in which practitioners sometimes coordinate and transform their conflicting ways of making sense of confusing predicaments. We should investigate the conventions and notations through which practitioners create virtual worlds-as diverse as sketch-pads, simulations, role-plays and rehearsals-in which they are able to slow down the pace of action, go back and try again, and reduce the cost and risk of experimentation. In such explorations as these, grounded in collaborative reflection on everyday artistry, we will be pursuing the description of a new epistemology of practice.

We should also investigate how it is that some people learn the kinds and levels of reflection-in-action essential to professional artistry. In apprenticeships and clinical experiences, how are textbook descriptions of symptoms and procedures translated into the acts of recognition and judgment, and the readiness for action characteristic of professional competence? Under what conditions do aspiring practitioners learn to see, in the unfamiliar phenomena of practice, similarities to the canonical problems they may have learned in the classroom? What are the processes by which some people learn to internalize, criticize and reproduce the demonstrated competence of acknowledged masters? What, in short, is the nature of the complex process we are accustomed to dismiss with the term, "imitation"? And what must practitioners know already, what kinds of competences, what features of stance toward practice, must they already have acquired in order to learn to construe their practice as a continuing process of reflection-in-action?

Clearly, just as some people learn to reflect-in-action, so do others learn to help them do so. These rare individuals are not so much "teachers" as "coaches" of reflection-in-action. Their artistry consists in an ability to have on the tip of their tongue, or to invent on-the-spot, the method peculiarly suited to the difficulties experienced by the student before them. And, just as professional artistry demands a capacity for reflection-in-action, so does the coach's artistry demand a capacity for reflection-inaction on the student's intuitive understanding of the problem at hand, the intervention that might enable them to become fruitfully confused, the proposal that might enable them to take the next useful step.

The development of forms of professional education conducive to reflection-in-action requires reflection on the artistry of coaching-a kind of reflection very nicely illustrated by 
the studies of case teaching conducted over the past ten years at the Harvard Business School. If educators hope to contribute to the development of reflective practitioners, they must become adept at such reflection on their own teaching practice.

In this way, perhaps, we will be heeding Everett Hughes' call for a way of undoing the bonds that have tied the professional schools to the traditions of the late 19th century university. At least, and at last, we will be getting some groups of young people who are free of those bonds, making them free to do something new and different.

\section{Notes}

1. For a discussion of Positivism and its influence on prevailing epistemological views, see Habermas (1968). And for a discussion of the influence of Positivist doctrines on the shaping of the modern university, see Shils (1978).

2. I have taken this term from Simon (1972) who gives a particularly useful sample of a well-formed problem.

3. For an example of multiple views of the malnourishment problem, see Berg, Scrimshaw and Call (1973).

4. I have taken this phrase from the work of psychiatrist, Harry Stack Sullivan.

5. As Bernstein (1976) has written: "There is not a single major thesis advanced by either nineteenth century Positivists or the Vienna Circle that has not been devastatingly criticized when measured by the Positivists' own standards for philosophical argument. The original formulations of the analytic-synthetic dichotomy and the verifiability criterion on meaning have been abandoned. It has been effectively shown that the Positivists' understanding of the natural sciences and the formal disciplines is grossly oversimplified. Whatever one's final judgment about the current disputes in the post-empiricist philosophy and history of science. . . there is rational agreement about the inadequacy of the original Positivist understanding of science, knowledge, and meaning."

6. Transcript of Nova, 29 March, 1983, "60 Minutes to Meltdown".

\section{References}

Ackoff, R. (1979). The future of operational research is past. Journal of Operational Research Society, 30(2), 93-104.

Alexander, C. (1964). Notes Toward the Synthesis of Forum. Cambridge, MA: Harvard University Press.

Alonso, W. (1963). Cities and city planners, Daedalus, 838.

Barnard, C. (1968). The Functions of the Executive (2nd Ed., p. 306). Cambridge, MA; Harvard University Press.

Berg, A., Scrimshaw, H. S., \& Call, D. L. (Eds.). (1973). Nutrition, National Development and Planning. Cambridge, MA: MIT Press.

Bernstein, R. (1976). The Restructuring of Social and Political Theory. New York:

Harcourt, Brace, Jovanovich.

Geertz, C. (1973). The Interpretation of Cultures, Selected Essays by Clifford Geertz. New York: Basic Books.

Glazer, N. (1974). The schools of the minor professions. Minerva, XII(3), 363. 
Gustafson, J. (1963). The clergy in the United States. Daedalus, 743.

Habermas, J. (1968). Knowledge and Human Interests. Boston, MA: Beacon Press.

Harrison, A. (1978). Making and Thinking. Indianapolis: Hacket.

Hughes, E. (1959). The study of occupations. In R. Merton, \& V. Broom (Eds.), Sociology Today. New York: Basic Books.

Lynn, K. (1963). Introduction to "The Professions". Daedalus, 649.

Polany, M. (1967). The Tacit Dimension (p.12). New York: Doubleday.

Rein, M., \& Schon, D. (1977). Problem-setting in policy research, In: C. Weiss, (Ed.), Using Social Research in Public Policy Making. Lexington, MA: D. C. Heath.

Ryle, G. (1949). On knowing how and knowing that. In The Concept of Mind (p.32). London: Hutcheson.

Schein, E. (1974). Professional Education (pp. 43-44). New York: McGraw Hill.

Shils, E. (1978). The order of learning in the United States from 1865 to 1920: The ascendancy of the universities. Minerva, XVI (2).

Simon, H. (1972). The Science of the Artificial. Cambridge, MA: MIT Press.

Veblen, T. (1968). The Higher Learning in America (Reprint of the 1918 edition). New York: Kelley.

Vickers, G. (1978). Unpublished memorandum, MIT. 